Creating clinical pharmacy capacity in Namibia: A collaboration to establish a post-

graduate pharmacy degree programme

Corkhill, N. L., Lates, J., Mubita, M., Kibuule, D., Jonkman, L., Hachey, D., Hunter, C., J., Bates, I. and Rennie, T. W.

Nicola L. Corkhill, BPharm (Hons), MSc Clinical Pharmacy,

University of Namibia, Namibia

Jennie Lates

University of Namibia, Namibia

Mwangana Mubita

University of Namibia, Namibia

Dan Kibuule

University of Namibia, Namibia

Lauren J. Jonkman, PharmD, MPH

Assistant Professor

University of Pittsburgh, School of Pharmacy

Department of Pharmacy and Therapeutics

David Hachey

Idaho State University

Department of Family Medicine 
Christian John Hunter

School of Medicine, University of Namibia, Namibia

Ian Bates

School of Pharmacy, University College London, UK

Corresponding author: Professor Timothy W. Rennie

School of Pharmacy, University of Namibia, Namibia

trennie@unam.na

Keywords: clinical pharmacy; postgraduate; Africa; Namibia

\section{Abstract}

In response to an identified need for postgraduate clinical pharmacy development and training in the country, a Master's degree was set up at the University of Namibia in 2016. The country has a considerable health burden of HIV and TB as well as a shortage of healthcare professionals. A UK clinical diploma model was adapted to meet the specific needs of the country and wider region, ensuring students could access the course over a sparsely populated, but large geographical spread, in addition to providing work-based learning, embedding research skills for future development, and focusing on the health needs of Namibia. The course uses online learning platforms and contact sessions to cover both knowledge and skill acquisition throughout the three years of the course. UK and US clinical pharmacists are utilised to provide specialist input, both remotely and within student workplaces, and further support has come from collaborations, including cross-site visits, 
with the UK-based pharmacy school whose diploma model was adapted. Challenges have included a shortage of clinical mentors, also compounding the students' difficulty in visualising their future roles, as well as lone practitioners finding it hard to attend all contact sessions. The initial dropout rates of earlier cohorts have since reduced with greater understanding of the programme, and enthusiasm for the course remains high. The aim for the Master's is to train students to become competent clinical pharmacists, thus having the knowledge and skills to mentor future cohorts of the course, as well as expanding the specialty within the country. 


\title{
Creating clinical pharmacy capacity in Namibia: A collaboration to establish a post-graduate pharmacy degree programme
}

\begin{abstract}
In response to an identified need for postgraduate clinical pharmacy development and training in the country, a Master's degree was set up at the University of Namibia in 2016. The country has a considerable health burden of HIV and TB as well as a shortage of healthcare professionals. A UK clinical diploma model was adapted to meet the specific needs of the country and wider region, ensuring students could access the course over a sparsely populated, but large geographical spread, in addition to providing work-based learning, embedding research skills for future development, and focusing on the health needs of Namibia. The course uses online learning platforms and contact sessions to cover both knowledge and skill acquisition throughout the three years of the course. UK and US clinical pharmacists are utilised to provide specialist input, both remotely and within student workplaces, and further support has come from collaborations, including cross-site visits, with the UK-based pharmacy school whose diploma model was adapted. Challenges have included a shortage of clinical mentors, also compounding the students' difficulty in visualising their future roles, as well as lone practitioners finding it hard to attend all contact sessions. The initial dropout rates of earlier cohorts have since reduced with greater understanding of the programme, and enthusiasm for the course remains high. The aim for the Master's is to train students to become competent clinical pharmacists, thus having the knowledge and skills to mentor future cohorts of the course, as well as expanding the specialty within the country.
\end{abstract}




\section{Background}

Namibia is an upper middle-income country in Southern Africa with extreme income inequality [1] and a disease burden typical of the region. As a large, sparsely populated country, there are few pharmacists working in the public hospitals across the country, and access to healthcare can be logistically and financially difficult. With an undergraduate pharmacy degree (BPharm) established in-country in 2010 in response to a significant workforce shortfall, future development needs were identified, including a need for postgraduate education (Figure 1) $[2,3,4]$. A postgraduate Master of Pharmacy in Clinical Pharmacy (MPharm) was therefore established in 2016 [5]. In order to realistically succeed as a degree programme in Namibia and be impactful, the degree needed to meet the following requirements: accessible resources through distance learning; content relevant to the country's health needs; emphasise practice-based learning in order to facilitate localised establishment of clinical pharmacy; emphasise research to promote future development; and finally, affordable costs to ensure all interested pharmacists can participate.

Figure 1: Establishing pharmacy education in Namibia (kindly reproduced from the International Pharmacy Journal)

\section{Need for the Programme}

Due to the significant paucity of pharmacists in the country, clinical pharmacy has not been practiced widely or routinely in Namibia. The high TB and HIV prevalence in the country increases medicine complexity and co-morbidities of patients, exacerbating the major physician shortages, such that there is a significant need for pharmacists to have clinical knowledge and skills beyond dispensing and supply. Clinical pharmacy is embedded within the BPharm programme; this clinical teaching is currently delivered by UNAM faculty [6], however, there is a need to train up existing pharmacists in practice to provide clinical teaching to students [7]. 


\section{Collaboration}

The UNAM MPharm degree closely followed the approach of the Joint Programmes Board (JPB), a funded partnership between the National Health Service (NHS) and nine Schools of Pharmacy in the UK $[8,9,10]$. The competency-based General Level Framework (GLF) developed as a product of the JPB initiative has also been used as a template for the global development of foundation-level competencies by the International Pharmaceutical Federation (FIP) [11]. The UNAM School of Pharmacy (SoP) used the JPB Post-Graduate Diploma in General Pharmacy Practice programme, based at the University College London School of Pharmacy (UCL), to benchmark its curriculum, adjusting the programme to meet the local needs and situation. UNAM sought input from UCL faculty, and three funded grants enabled faculty exchange to develop and implement the programme, with UCL faculty delivering specific training in Namibia to increase local training capacity. UNAM faculty visited the UK for exposure to the work-based training model of the UCLdeveloped programme. In addition to this academic collaboration, one UK-based and two US-based senior clinical faculty have supported the development of the programme through to implementation in clinical mentorship, training, and assessment. Finally, senior faculty in the UNAM School of Medicine have provided support to the implementation of the programme. These supportive inter-institutional and cross-professional collaborations have been essential to programme implementation and have ensured the relevance of training, both locally and internationally, as well as providing on-going external peer review.

\section{Structure of the programme}

The Namibian MPharm is a three-year post-graduate degree leading to a Master of Pharmacy. The programme is work-based to ensure that students can demonstrate their competence in a practice setting, and aligns with the FIP global Workforce Development Goal 2 (Foundation Training for early year pharmacists) [12]. All enrolled students must be registered and practising pharmacists. The programme is divided into themes with relevant learning and tasks for student completion (Table 1). 
Evidence of learning is demonstrated through a portfolio and a variety of summative and formative assessments [13,14]. Support for work-based assessment was one of the first areas of implementation support provided through the UCL-UNAM collaboration.

Table 1: Summary of programme themes, assessment approach and evidence of learning

Alongside taught topics, students develop their research proposal in the first year, and conduct a therapeutic review task. The second year incorporates clinical services and operational services, as well as ongoing knowledge provision and assessment regarding common non-communicable diseases. Students must carry out either a drug use review or clinical audit, and gain the necessary ethical approvals for their research. The third year of the programme further develops the students' clinical skills through a Defined Area of Practice, currently either inpatient pharmacy or outpatient pharmacy practice, recognising the need for pharmacists to have generalist knowledge across their specific setting. A change management project is developed throughout the year and presented at the end, in addition to completion and submission of their research mini-thesis.

\section{Delivery of the Programme \& Resource Access}

The programme was designed to meet the needs of pharmacists living and working in Namibia, and with the geographical spread of potential students and the size of the country, the programme must be accessible from anywhere in the country, without students having to regularly travel long distances for teaching sessions. Additionally, as all students are working full-time, making time for numerous contact sessions can be challenging. The programme was therefore designed as distance learning, with four, three-day contact sessions in Windhoek, the capital, per year, and a fifth period for exams. Programme content is placed on the university's online learning management system, enabling reliable communication with students, remotely accessible assessments, and access to 
resources such as journal articles, regardless of location. Assignments can also be administered, and feedback provided, allowing for both synchronous and asynchronous teaching and assessment. On-site teaching sessions are delivered by UNAM faculty, including visiting lecturers from abroad who are clinical pharmacy specialists. They are utilised to teach and assess students, provide clinical mentorship, and develop course content and assessments. The programme includes work-based assessments, done in person or online via webcam (Table 2), and contact sessions focus on handson, applied learning including case presentations, journal club, and ward-based learning within local hospitals.

\section{Challenges}

Despite great enthusiasm for the programme from students, particularly given the chance for further professional development in Namibia [15], as of the current enrollment, 33 students have commenced the MPharm with nine dropping out. This is mostly due to work contract termination of non-Namibians in Namibia, plus one student repeating a year of studies. Drop-out rates have reduced in subsequent intakes, possibly as the expectations of the MPharm are better communicated, but this remains a concern. In order to transform pharmacy practice in the clinical field and have a measurable impact on patient outcomes, there needs to be a substantial uptake and output of the degree. The students currently enrolled on the programme represent approximately $5 \%$ of the pharmacist population in Namibia and, therefore, are probably already making an impact. Students with sporadic internet access around the country have noted access difficulties to online resources at times and the faculty now download much of the content and resources at contact sessions to ensure student access. The large geographical spread of the students, as well as work commitments, particularly for pharmacists in solo practice, have meant that not all students attend all contact sessions. These challenges have been important to recognise, in order to create systems to improve the way that students access and engage in the programme. 
More challenging for some students has been a lack of clinical pharmacy mentors in their local health facilities. With clinical pharmacy not being practised in their places of work, it has been hard for some students to visualize their future role, and to find work-based mentors who can facilitate and nurture their development. Local clinical mentors in or near the student's workplace (including medical practitioners) are therefore identified, and supplemented by UNAM staff and visiting faculty conducting on-site visits for work-based assessment and clinical mentoring. Contact sessions emphasize the role of a clinical pharmacist, and the skills and application to implement such a service, with time included to take student to the nearby hospitals for clinical supervision. As the MPharm progresses and future cohorts graduate, clinical mentors will become more widely available and this challenge should recede in time. In turn, this will create a hub of clinical mentors in Namibia that could potentially serve surrounding countries where clinical pharmacy is also not yet established.

\section{Future Direction}

Visiting faculty will continue to build on the clinical skills students have already developed, encouraging the students to become mentors for future cohorts of MPharm students. As current students specialise within their areas, the available DAP topics for future cohorts will grow and create a pool of clinical mentors. With a student from Botswana already enrolled, it is hoped that the degree may be desirable to students from other Southern African countries, provided they can surmount the logistical requirement of attending contact sessions and exams.

Having instilled research methods into students' routine practice, the intention is that they will go on to study for a UNAM-supported PhD, or otherwise specialise to further create capacity and expertise in Namibia and the surrounding region.

\section{Conclusions}


Universal health cover is a critical health priority for the nation and pharmacy is a key component for achieving this, impacting on workforce development and planning. The development and implementation of this new programme for training clinical pharmacists in Namibia builds on the national workforce development agenda of training pharmacists and pharmaceutical technicians incountry and strengthening capacity and sustainability therein. We have developed key partners through collaborative working and implemented a workplace education model on a strategic basis to tackle the sustainability and resource challenges in Namibia. Work-based learning within this model, with the use of evidence-based and adapted tools and mechanisms, has started a transformative change in the Namibian pharmacy workforce.

Introducing the UNAM postgraduate clinical MPharm has responded to a pressing need identified in the local context. While its implementation has not been without challenges, faculty continue to develop solutions rooted in the local context to meet those challenges. Though clinical pharmacy is in its infancy in Namibia, a sustainable, tailored approach to training clinical pharmacists has been embraced, maximising the impact of this programme. Future work will focus on establishing if clinical practice in Namibia has a measurable impact and quantifying other outcomes of the programme such as publications in reputable journals. 


\section{References}

1. United Nations Development Programme. Human Development Indices and Indicators; 2018 Statistics Update. Available at: http://hdr.undp.org/en/2018-update, accessed $27^{\text {th }}$ September 2018

2. Namibia's First School of Pharmacy: From Creation to Graduation. (2015). [Blog] USAID/SIAPS. Available at: http://siapsprogramme.org/2015/04/27/namibias-first-school-of-pharmacy-fromcreation-to-graduation/, accessed $24^{\text {th }}$ September 2018

3. Mapping educational opportunities and resources for health-care workers to learn about antimicrobial resistance and stewardship. Geneva: World Health Organization; 2017 (Human Resources for Health Observer, 21).

4. Rennie $\mathrm{T}$, Coetzee $\mathrm{N}$, Hunter $\mathrm{CJ}$ et al. Piloting a new pharmacy internship support programme in Namibia. Pharmacy Education, 2018; 18 (1): 88 - 90

5. Brock TP, Brown AN, Rennie T et al. Global pharmacy education: are we nearly there yet? International Pharmacy J. 2012; 28 (1): 4-11

6. Hachey D, Jonkman L, Corkhill N, Rennie T, et al. Establishing Clinical Pharmacy Services in Namibia Through Educational Partnerships. J Am Coll Clin Pharm 2019; 8 May

7. Rudall N, Kalemeera F \& Rennie T. Implementing clinical pharmacy within undergraduate teaching in Namibia. International J Clin Pharmacy, 2015; 37 (3): 427-429

8. Udoh A, Bruno A, Bates I, Galbraith K. Int J Pharm Pract. 2018 Jan 4. Transnational comparability of advanced pharmacy practice developmental frameworks: a country-level crossover mapping study.

9. Kirsten Galbraith, lan Coombes, Andrew Matthews, Debra Rowett, Lina R. Bader and Ian Bates, Advanced pharmacy practice: aligning national action with global targets, Journal of Pharmacy Practice and Research, 47, 2, (131-135), (2017).

10. Meštrović, A., Staničić, Z., Hadžiabdić, M.O., Mucalo, I., Bates, I.D., Duggan, C.A., Carter, S., Bruno, A., \& Košiček, M. (2012). Individualized education and competency development of Croatian community pharmacists using the general level framework. American journal of pharmaceutical education, $762,23$.

11. International Pharmaceutical Federation. (2012). Pharmacy Education Taskforce - A Global Competency Framework (GbCF v1). Available at:

https://fip.org/files/fip/PharmacyEducation/GbCF/GbCF v1 online A4.pdf

12. International Pharmaceutical Federation. (2016). Pharmaceutical Workforce Development Goals. Available at: https://fip.org/files/fip/PharmacyEducation/2016 report/2016-11-Educationworkforce-development-goals.pdf

13. Rennie T. Chapter 4: Assessing learning. In: Carter, S.L., et al., (2011). Facilitating learning in healthcare. Pharmaceutical Press. London

14. Davies JG, Ciantar J, Jubraj B, Bates IP. Use of a multisource feedback tool to develop pharmacists in a postgraduate training programme. Am J Pharm Educ. 2013 Apr 12;77(3):52. 
15. Elmes AT, Jonkman LJ, Mubita M, et al. Factors for enrollment in the work-based clinical Master of Pharmacy at the University of Namibia. Poster presented at International Pharmacy Federation Conference, 2018, Glasgow, UK 
Figure 1: Establishing pharmacy education in Namibia (kindly reproduced from the International Pharmacy Journal

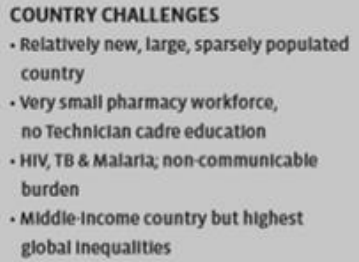

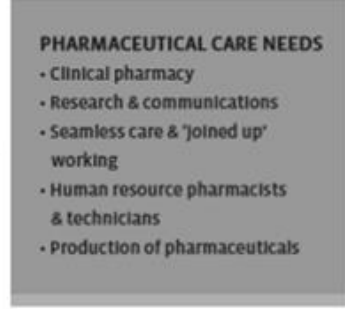

ROBUST PHARMACY

EDUCATION

- Undergraduate

- postgraduate

- Technical Training

- Pharmaceutical production

- Research programme

\section{IN SITU RESOURCE}

- Pharmacy Degree Programme

- Pharmacists Assistants Training

- Professional \& Medicines Regulators.

- Partiamentary Mandale (Pharmacy Act)

- Established community Pharmacy sector

- Estabilshed Public sector components

- Supportive Non-Govt, organisations

- Professional Representation

Improved patient outcomes through access \& rational medicines use - Improved career pathways in private sectors

- Improved public health through evidence based coordinated approach 
Table 1: Summary of programme themes, assessment approach and evidence of learning

\begin{tabular}{|c|c|c|c|}
\hline & Year One & Year Two & Year Three \\
\hline Themes & $\begin{array}{l}\text { Infectious diseases, } \\
\text { focusing on HIV \& TB } \\
\text { Public health \& } \\
\text { epidemiology } \\
\text { Research methods }\end{array}$ & $\begin{array}{l}\text { Clinical services } \\
\text { Operational services } \\
\text { Non-communicable } \\
\text { diseases }\end{array}$ & $\begin{array}{l}\text { Defined area of } \\
\text { practice: inpatient or } \\
\text { outpatient pharmacy }\end{array}$ \\
\hline Research & Research proposal & $\begin{array}{l}\text { Peer review } \\
\text { presentation } \\
\text { Ethics approval }\end{array}$ & Mini-thesis \\
\hline Task-based assignments & Critical appraisal & $\begin{array}{l}\text { Drug use } \\
\text { review/clinical audit }\end{array}$ & $\begin{array}{l}\text { Change management } \\
\text { project }\end{array}$ \\
\hline $\begin{array}{l}\text { Evidence of learning } \\
\text { taught subjects }\end{array}$ & \multicolumn{3}{|c|}{$\begin{array}{l}\text { Assignments } \\
\text { Knowledge based exams (MCQ/short answer) } \\
\text { Competency exams (OSCEs) }\end{array}$} \\
\hline $\begin{array}{l}\text { Evidence of } \\
\text { experiential/practice- } \\
\text { based learning }\end{array}$ & \multicolumn{3}{|c|}{$\begin{array}{l}\text { Work-based assessments (e.g. CEx, CbD) } \\
\text { Portfolio review } \\
\text { Viva voce }\end{array}$} \\
\hline
\end{tabular}

OSCE - Observed Structured Clinical Examination; MCQ - Multiple Choice Questions; CEX - Clinical

Examination; CbD-Case-based Discussion 